\title{
AN OVERVIEW OF IMMUNOLOGICAL AND GENETIC METHODS FOR DETECTING SWINE CORONAVIRUSES, TRANSMISSIBLE GASTROENTERITIS VIRUS, AND PORCINE RESPIRATORY CORONAVIRUS IN TISSUES
}

\author{
Theerapol Sirinarumitr, ${ }^{1.3}$ Prem S. Paul,' Patrick G. Halbur, ${ }^{2}$ and John P. \\ Kluge $^{3}$ \\ Iowa State University \\ College of Veterinary Medicine \\ 'Veterinary Medical Research Institute \\ ${ }^{2}$ Veterinary Diagnostic Laboratory \\ ${ }^{3}$ Veterinary Pathology \\ Ames, Iowa 50011
}

\section{SUMMARY}

Transmissible gastroenteritis (TGE) is an enteric disease of swine caused by a coronavirus, designated as transmissible gastroenteritis virus (TGEV). Commonly used methods for TGEV detection include viral isolation and detection of the viral antigen by indirect immunofluorescence (IFA), immunoperoxidase, and immunogold silver staining. Each of these techniques has some advantages and disadvantages. In general IFA and immunohistochemistry are preferred over viral isolation as TGEV isolation is not very reliable because not all field isolates replicate in cell cultures. The diagnosis of TGEV has become more complicated since the emergence of porcine respiratory coronavirus (PRCV). PRCV is believed to be a TGEV mutant, and can not be easily differentiated from TGEV by immunological tests. Nucleic acid probes and polymerase chain reaction (PCR) have successfully been used to detect and differentiate these viruses. These techniques can detect viral nucleic acids in the specimen but do not provide information on the cell types infected by these viruses. Recently we have developed isotopic and nonisotopic in situ hybridization techniques (ISH) for the detection of these viral nucleic acids in formalin-fixed paraffin-embedded tissues. Furthermore, this procedure can differentiate between TGEV-and PRCV-infected cells. By ISH, TGEV is detected in the mature absorptive enterocytes of tissues infected by TGEV and the crypt epithelial cells are also infected but to a lesser extent. For PRCV, the main infected cells are epithelial cells of the 
bronchioles, type II pneumocytes, and alveolar and septal macrophages. ISH is an excellent tool for studying molecular pathogenesis of these two viruses especially when used in combination with immunohistochemistry.

\section{INTRODUCTION}

Transmissible gastroenteritis (TGE) is an economically important disease because it is highly contagious and characterized by vomiting, severe diarrhea and high mortality in piglets during the first few weeks of life. Transmissible gastroenteritis virus (TGEV) belongs to the genus coronavirus of the family Coronaviridae and is a pleomorphic enveloped virus, with a single-stranded positive-sense RNA genome (Saif \& Wesley, 1994). The full-length negative-sense RNA is first synthesized from the positive-sense RNA genome after infection and is used as the template for synthesis of the 3'-terminal nested set of 7-8 subgenomic mRNAs (Britton et al., 1989; Spaan et al., 1988; Wesley et al., 1990). The subgenomic mRNAs, with the exception of the smallest one, are polycistronic in nature, and only the unique $5^{\circ}$ open reading frame is translated (Sanchez et al., 1992; Spaan et al., 1988). TGEV uses the spike proteins to bind with the receptors on the cell membrane of the mature absorptive enterocytes. The cell receptors for TGEV are thought to be aminopeptidase-N (Delmas et al., 1992) and a second putative receptor of $200 \mathrm{kDa}$ (Weingartl \& Derbyshire, 1994). These receptors are present only on the cell membrane of absorptive enterocytes and are absent on the cell membrane of crypt epithelial cells. TGEV replicates in the cytoplasm of the mature absorptive enterocytes (Saif \& Wesley, 1994) and matures by budding through the endoplasmic reticulum (Thake et al., 1968; Pensaert et al., 1970; Wagner et al., 1968). TGEV damages villous enterocytes and causes atrophy characterized by blunted and denuded villi of the small intestines which results in malabsorptive diarrhea. TGEV has also been shown to replicate to some extent in the respiratory tissue (La Bonnardiere et al., 1983; Laude et al., 1993).

PRCV was first isolated in 1984 from pigs in Belgium which were seropositive for TGEV but did not have clinical disease characteristic of TGE (Pensaert et al., 1986). PRCV infection is now widespread in European swine. PRCV has also been isolated in the United States (Hill et al., 1989; Wesley et al., 1990; Vaughn et al., 1994). PRCV causes subclinical disease to mild-moderate pneumonia in swine (Cox et al., 1990; O‘Toole et al., 1989; Halbur et al., 1993). PRCV replicates mainly in the respiratory tissues such as bronchiolar epithelial cells, type II pneumocytes, alveolar and septal macrophages, and type I pneumocytes (Cox et al., 1990; O‘Toole et al., 1989; Sirinarumitr et al., 1996). PRCV antigen was detected in unidentified cells in the lamina propria of the small intestines (Cox et al., 1990).

PRCV is believed to be a TGEV mutant, as it has been shown to be antigenically and genetically closely related to enteropathogenic TGEV but has different tissue tropism. PRCV is different from TGEV in that PRCV has a 621-681 nucleotide deletion in the 5* end of the $S$ gene and deletions in gene 3 and 3-1 which render these mRNAs truncated or undetectable in the infected cells (Britton et al., 1991; Laude et al., 1993; Paul et al., 1992; Paul et al., 1994; Rassachaert et al., 1990; Sanchez et al., 1992; Vaughn et al., 1994; Vaughn et al., 1995; Wesley et al., 1990; Wesley et al., 1990a). The deletion in the S gene is believed to play a role in the change of tissue tropism of PRCV. 


\section{METHODS FOR DETECTION OF VIRAL ANTIGEN AND VIRAL NUCLEIC ACID IN TISSUE}

There are several methods to identify TGEV antigen or nucleic acid in the tissues such as immunofluorescence technique (Frederick et al., 1976; Morin et al., 1973; Shepherd et al., 1979), peroxidase-antiperoxidase staining technique (Chu et al., 1982), immunogold silver staining (Larochelle et al., 1993), dot blot hybridization (Paul et al., 1994; Shockley et al., 1987), slot blot hybridization (Wesley et al., 1991b), reverse transcriptase polymerase chain reaction (RT-PCR) (Vaughn et al., 1994; Vaughn et al., 1995), and in situ hybridization (Sirinarumitr et al., 1996). These techniques will be reviewed but major emphasis will be placed on the newly developed ISH technique (Sirinarumitr et al., 1996).

\section{Virus Isolation}

Virus isolation is one of the major methods for TGEV diagnosis, however many TGE virus isolates do not replicate well in cell cultures (Vaughn et al., 1993). There are several cell lines that can be used to isolate or identify TGEV and PRCV such as primary and secondary porcine kidney cells, continuous kidney cell lines, McClurkin swine testical cell line (ST), primary porcine salivary gland cells, and porcine thyroid cells (Saif \& Wesley, 1994). ST cells are the cells of choice for isolation and identification of TGEV and PRCV. Lungs or small intestines are homogenized in Eagle's minimal essential medium $(20 \% \mathrm{w} / \mathrm{v})$, clarified at $1,000 \mathrm{Xg}$ for $10 \mathrm{~min}$, and filtered through a $0.22 \mu \mathrm{m}$ filter. Nasal swabs are the samples for isolation of PRCV. Three-to five-day-old ST cell monolayers in $25 \mathrm{~cm}^{2}$ flasks are inoculated with $0.2 \mathrm{ml}$ of filtrate for 1 hour at $37^{\circ} \mathrm{C}$, and then the monolayer is washed and new medium is added. The cultures are incubated at $37^{\circ} \mathrm{C}$ for 48 hours and observed daily for cytopathic effect. The cytopathic effect of TGEV and PRCV in ST cells is characterized by rounded to elongated cells and syncytial cell formation. If no cytopathic effect is observed, the cells in flasks are frozen and thawed 3 times, and cell lysates are inoculated onto new ST cell monolayers. Samples are passed 3 times or more. The presence of TGEV and PRCV can be confirmed by a variety of immunological and genetic techniques mentioned in this paper.

\section{Immunofluorescence Antibody Technique}

The fluorescence antibody (FA) technique is the most commonly used method for TGEV diagnosis because it is sensitive, rapid and relatively inexpensive. This technique can be done as a direct or an indirect method. The direct FA technique uses anti-TGEV antibody which is conjugated with fluorescein. As in direct FA, the IFA technique uses anti-TGEV antibody as a primary antibody and fluorescein-labeled secondary antibody to detect the primary antibody. For both techniques, frozen tissues are sectioned by cryostat-microtome at $-20^{\circ} \mathrm{C}$. Sections are placed on clean glass slides, fixed in chilled acetone, and dried. In the case of direct FA technique, sections are incubated with anti-TGEV antibody in a humidified chamber, washed, dried, and examined by using a fluorescence microscope. For IFA technique, sections are incubated with fluorescein-labeled secondary antibody before examining with a fluorescence microscope. TGEV antigen has been detected in the mature absorptive enterocytes but not in the crypt epithelial cells (Bohl et al., 1989; Frederick et al., 1976; Morin et al., 1973; Pensaert et al., 1970; Saif \& Wesley, 1994; Shepherd et al., 1979; Woods et al., 1981). This technique is also used for detection of PRCV in tissues by using an anti-TGEV antibody (Cox 
et al., 1990a; Cox et al., 1990b). PRCV antigen is detected mainly in alveolar cells but also to a lesser extent in epithelial cells of nasal mucosa, trachea, bronchi and bronchioles, alveolar macrophages, and in tonsils. The antigen is also found in unidentified cells located in lamina propria of the small intestines. Major problems with this technique are the lack of sensitivity and specificity of the antibody, loss of infected cells due to the quality of sample or loss during processing, poor definition of tissue morphology and cell type, lack of permanent preparation, and cross-reaction with feline infectious peritonitis virus (FIPV), canine coronavirus (CCV) (Horzinek et al., 1982; Woods et al., 1981) and PRCV (Callebaut et al., 1988).

\section{Immunohistochemistry}

There are several immunohistochemistry techniques such as immunoperoxidase and immunogold for the detection of TGEV and PRCV in tissues. Immunoperoxidase-base antigen detection techiques have been done using frozen tissues for TGEV (Chu et al., 1982) and PRCV (Van Nieuwstadt et al, 1989). Frozen tissues are treated as in the FA technique, except for the detection step where the peroxidase-antiperoxidase system is used. The result can be seen by the color development which is the result of the reaction between peroxidase, hydrogen peroxide and substrate (diaminobenzidine). The distribution of the TGEV antigen is similar to the FA technique and the distribution of the PRCV antigen is

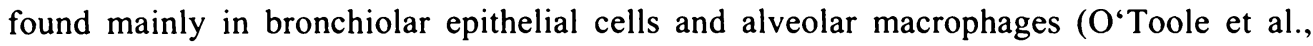
1989) which is different from the FA results reported by Cox et al. (1990).

Immunohistochemistry (IHC) can be used with formalin-fixed paraffin-embedded tissues. Now this technique has been used routinely for TGEV and PRCV diagnosis at the Veterinary Diagnostic Laboratory, College of Veterinary Medicine, Iowa State University. Methods for IHC are similar to that described for porcine reproductive and respiratory syndrome virus (Halbur et al., 1994). Tissues are sectioned, deparaffinized, and rehydrated as in the immunoperoxidase technique. The primary monoclonal antibody to nucleocapsid protein (kindly provided by Dr. Linda Saif, The Ohio State University) is applied to the tissue sections and followed by application of biotinylated secondary antibody. Sections are treated with peroxidase labeled streptavidin (LSAB) and are incubated with hydrogen peroxide and diaminobenzidine tetrahydrochloride (DAB). The cytoplasm of infected cells stain deep brown as shown in Fig.1. The viral antigen distribution is similar to that observed by FA and immunoperoxidase techniques on frozen tissue sections. Tissue morphology and cellular detail is far superior in the formalin-fixed tissues. This technique has several advantages over the FA technique because it can be used with formalin-fixed paraffin-embedded tissues, for retrospective study, and with a concurrent study of viral antigen distribution and histopathologic changes.

For the immunogold silver staining method (IGSS), formalin-fixed paraffin embedded sections are treated with protease, stained with anti-TGEV antibody and incubated with colloidal gold-labeled protein A (Larochelle et al., 1993). Then, the sections are incubated with a silver enhancement solution. The distribution of antigen positive cells are similar to the method mentioned above. This method has advantages compared to immunoperoxidase and immunohistochemistry in that it is safer and can be used for electron microscopy.

\section{Dot and Slot Blot Hybridization}

Total intracellular RNAs are isolated from infected ST cells by guanidinium isothiocyanate and centrifugation through a $\mathrm{CsCl}$ cushion (Wesley et al., 1990). The total RNAs are then applied on the nitrocellulose membrane (Shockley et al., 1987; Vaughn et al., 


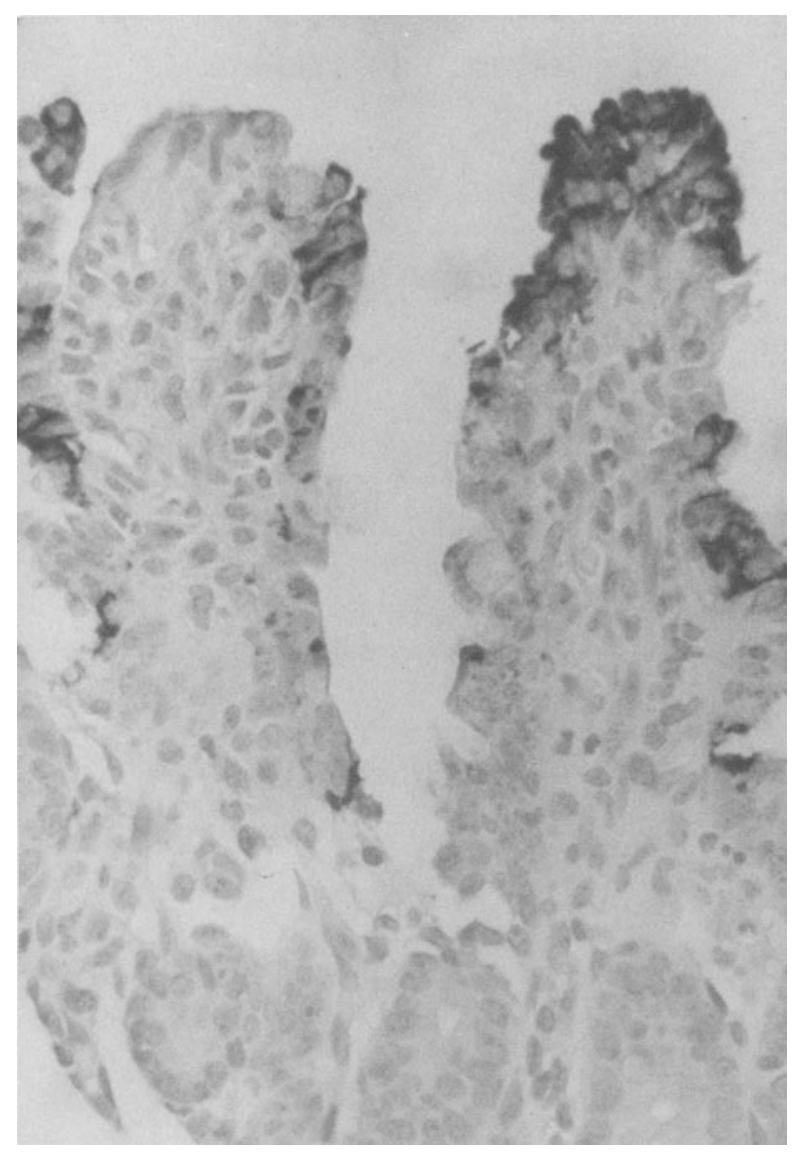

Figure 1. Section of small intestines with positive TGEV antigen staining of mature absorptive enterocytes by immunohistochemistry technique.

1996) or nylon membrane (Wesley et al., 1991b) by using a dot blot or slot blot apparatus. The nitrocellulose membrane is air dried and baked at $76^{\circ} \mathrm{C}$ for $90 \mathrm{~min}$ in the oven or the nylon membrane is exposed to UV light for cross-linking RNA to the membrane. The membrane is prehybridized, hybridized with ${ }^{32} \mathrm{P}$-labeled or nonisotopic cDNA probes, and hybridization signal captured by exposure of X-ray film. By using slot blot hybridization, Wesley et al. (1991b) and Vaughn et al. (1996) have been able to differentiate TGEV from PRCV.

\section{Reverse Transcriptase Polymerase Chain Reaction}

First strand cDNA is synthesized from the total RNA of TGEV- or PRCV-infected ST cells by using avian myeloblastosis virus reverse transcriptase and random primers. The cDNA-RNA hybrid is amplified by PCR with Taq DNA polymerase and specific primers for TGEV and PRCV (Paul et al., 1994; Vaughn et al., 1996; Vaughn et al., 1995). The PCR products are run in agarose gel electrophoresis, and gels are stained with ethidium bromide and viewed with UV light. The PCR product of TGEV is about $2.4 \mathrm{~kb}$ 
but the PCR product for PRCV is smaller by $600-700$ nucleotides depending on the isolate (Jackwood et al., 1993; Vaughn et al., 1994; Vaughn et al., 1995).

\section{In situ Hybridization (ISH) for TGEV and PRCV}

Both frozen sections and formalin-fixed paraffin-embedded sections can be used for ISH. For development of the ISH technique, we used 2 probes prepared from plasmid pPSP.FP 1 and plasmid pPSP.FP ${ }_{2}$ (Sirinarumitr et al., 1996; Vaughn et al., 1994). The plasmid pPSP.FP, contains the $S$ gene segment from the nucleotides 1678 to 2250 (Britton \& Page, 1990) which is present in TGEV but is deleted in all PRCV isolates (Paul et al., 1994; Vaughn et al., 1994, Vaughn et al., 1995). The plasmid pPSP.FP ${ }_{2}$ contains the S gene segment from nucleotides 1678 (Britton \& Page, 1990) to 2483 (Rassachaert and Laude, 1987). Briefly, sections are deparaffinized, treated with proteinase K, and acetylated before hybridization with ${ }^{35} \mathrm{~S}$-labeled RNA probe (Sirinarumitr et al., 1996). Then the sections are hybridized with probe in hybridization buffer at $52^{\circ} \mathrm{C}$ for at least 16 hours, followed by treatment with RNase A and passed through a series of standard sodium citrate solutions. The slides are exposed to X-ray films for rapid results or coated with autoradiographic emulsion gel to detect viral nucleic acid positive cells. Coated slides and $\mathrm{X}$-ray films are developed and observed for the hybridization signals.

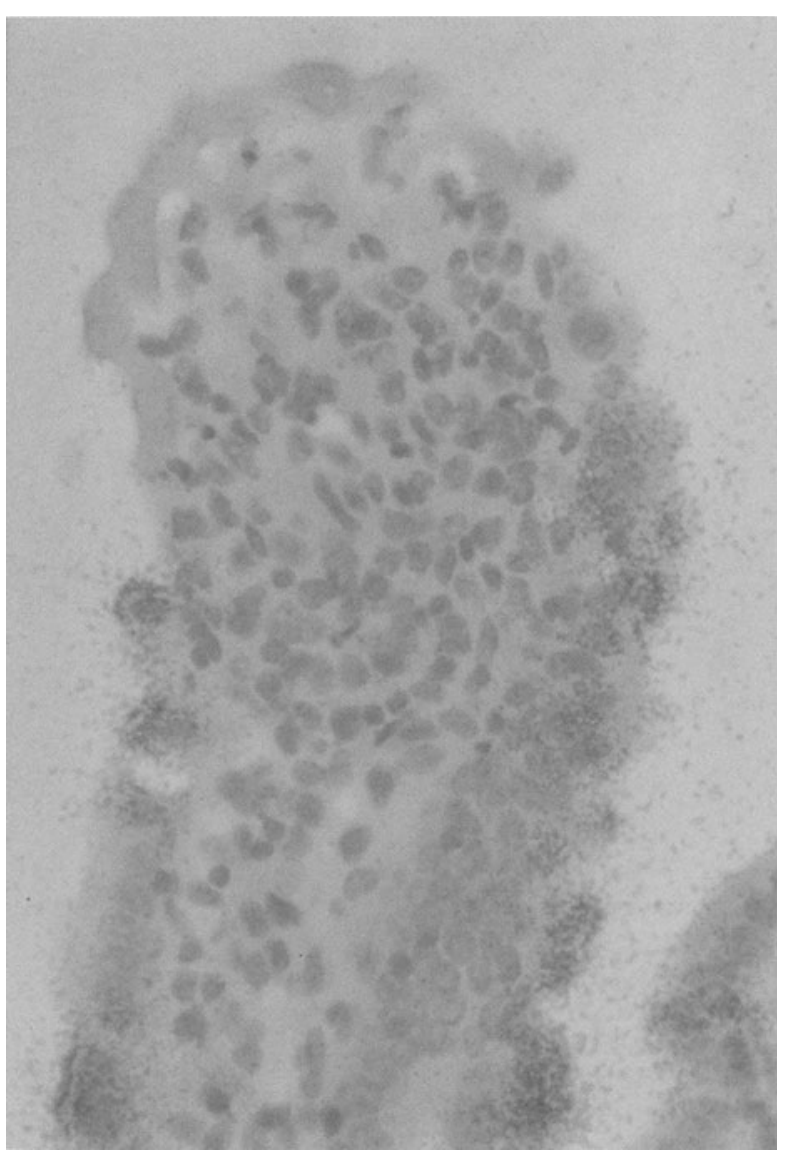

Figure 2. Photograph of formalin-fixed paraffin-embedded sections from the small intestines of uninoculated control (A) and TGEV-inoculated pig (B and C) hybridized with ${ }^{35}$ S-RNA probe (B) and digoxigenin-labeled RNA probe $(C)$ prepared from $p P S P . F P_{1}$. In the case of ${ }^{35} \mathrm{~S}$ RNA probe, the heavy silver grains are localized over the cytoplasm of the mature absorptive enterocytes and the dark purple color in the cytoplasm of the same cell type in the case of digoxigenin-labeled RNA probe. 
Figure 3. Photograph of formalin-fixed paraffin-embedded sections from lungs of uninoculated control (A) and PRCVinoculated pig (B) hybridized in situ with ${ }^{35} \mathrm{~S}-\mathrm{RNA}$ probe produced from plasmid pPSP.FP, and exposed to emulsion for 2 days. ISH signals can be observed in the cytoplasm of the bronchiolar epithelial cells of small bronchioles of PRCV-inoculated pigs

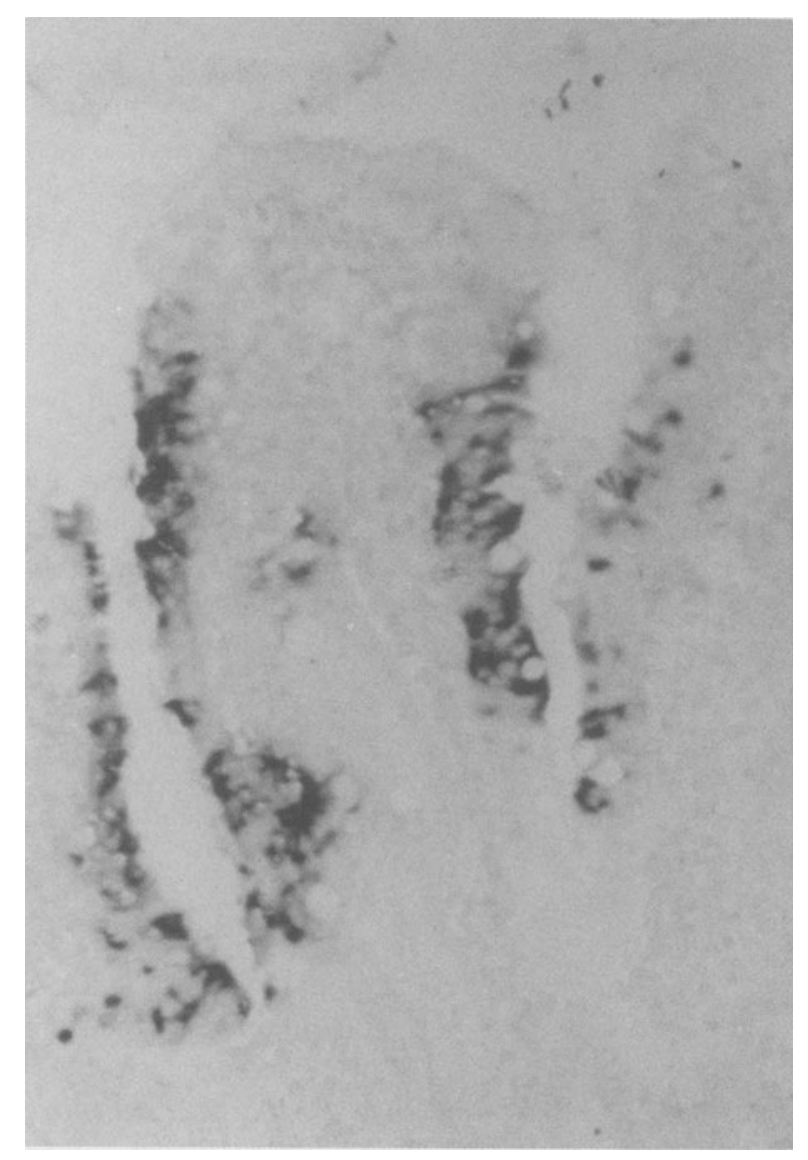

Recently, we have developed a digoxigenin-labeled RNA probe for nonisotopic ISH as the nonradioisotope probe has longer shelf life, is safer and more user friendly. Sections are treated and hybridized in the same way as isotopic ISH. The difference is only the detection step. Sections are washed briefly in maleic acid buffer $(100 \mathrm{mM}$ Tris- $\mathrm{HCl}$ and 150 $\mathrm{mM} \mathrm{NaCl}$ at $\mathrm{pH} \mathrm{7.5)} \mathrm{and} \mathrm{are} \mathrm{blocked} \mathrm{with} 3 \%$ blocking reagent in maleic acid buffer for 30 minutes at room temperature in a humidified chamber. Anti-digoxigenin-alkaline phosphatase $(1: 300)$ is applied to the slides for $2 \mathrm{~h}$ at room temperature and then washed 3 times for 10 minutes at room temperature in maleic acid buffer. Slides are equilibrated for 5 minutes at room temperature in detection buffer containing $100 \mathrm{mM}$ Tris- $\mathrm{HCl}, 100 \mathrm{mM}$ $\mathrm{NaCl}$, and $50 \mathrm{mM} \mathrm{MgCl}{ }_{2} \mathrm{pH}$ 9.5. Substrate containing $45 \mu \mathrm{l}$ of NBT solution and $35 \mu \mathrm{l}$ of BCIP solution in $10 \mathrm{ml}$ of detection buffer is then applied to the slides for 30 minutes at room temperature. The color development is stopped by rinsing with deionized water, and slides are counterstained with nuclear fast red for $3 \mathrm{~min}$. Slides are washed in 3 changes of deionized water and mounted with aquamount.

The autoradiography results using X-ray films clearly distinguished sections from TGEV-inoculated and non-inoculated animals. Sections of duodenum, anterior jejunum, posterior jejunum, anterior ileum, and posterior ileum from inoculated animals have heavy dark lines of silver grains along the mucosal layer. Both isotopic and nonisotopic ISH demonstrate the presence of TGEV nucleic acid in the same tissues and cells as those with 
TGEV antigen detected by the immunoperoxidase, immunohistochemistry, and immunogold procedures. One exception was that TGEV nucleic acid was also detected in crypt epithelial cells of TGEV infected animals which has not been shown with other techniques (Sirinarumitr et al, 1996). ISH allows visualization of heavy silver grains along the apical cell membrane of the infected cells indicating the possible route of entry and release of TGEV and also PRCV from the infected cells. This has also been shown by infected polarized epithelial cells and transmission electron microscopy (Rossen et al., 1994; Thake, 1968).

For PRCV, the viral nucleic acid positive cells are most often in the bronchiolar epithelial cells, especially terminal bronchioles, followed by type II pneumocytes, alveolar macrophages and type I pneumocytes. The hybridization signals are also found over the necrotic epithelial cells that slough into the lumen of the bronchioles, and over the alveolar macrophages in the exudate in the alveoli and bronchioles.

ISH technique has the same advantages as the techniques mentioned above and can also be used for electron microscopy. ISH can overcome the antigen degradation in the tissue which is a common problem of the techniques that detect viral antigens. ISH may be an appropriate tool to gain a better understanding of the molecular pathogenesis of TGEV and PRCV associated disease especially when combined with immunohistochemical techniques.

\section{CONCLUSION}

The clinical manifestation, diagnosis, and basic pathogenesis of TGEV and PRCV have been well described. The molecular pathogenesis of TGEV and PRCV infections has not been well studied in detail. Understanding the pathogenesis of porcine coronavirus infections has progressed by use of IHC for detection of the distribution of viral antigen in situ. Several molecular tools are now available for the study of the viral nucleic acid distribution in tissues. ISH is one such a tool that can be used for the study of molecular pathogenesis of TGEV and PRCV infections. The double-labeling techniques using ISH and immunohistochemistry should facilitate studies to better understand the molecular pathogenesis of these two porcine coronaviruses. The use of non-radioactive probes for ISH should facilitate the use of ISH in diagnostic laboratories as well.

\section{REFERENCES}

Bohl, E. H., and Pensaert, M. B., 1989, Transmissible gastroenteritis virus (classical enteric variant) and transmissible gastroenteritis virus (respiratory variant). In: M. B. Pensaert (Ed), Virus infections of porcines, Elsevier Science Publishers B.N., Amsterdam, pp.139-165.

Britton, P., Mawditt, K. L., and Page, K. W., 1991, The cloning and sequencing of the virion protein genes from a British isolate of porcine respiratory coronavirus: comparison with transmissible gastroenteritis virus genes, Virus Res. 21:181-198.

Britton, P., and Page, K. W., 1990, Sequence of the S gene from a virulent British field isolate of transmissible gastroenteritis virus, Virus Res. 18:71-80.

Callebaut, P., Correa, I., Pensaert, M., et al., 1988, Antigenic differentiation between transmissible gastroenteritis virus of swine and a related porcine respiratory coronavirus, J. Gen. Virol. 69:1725-1730.

Chu, R. M., Li, N. J., Glock, R. D., and Ross, R. F., 1982, Application of peroxidase-antiperoxidase staining technique for detection of transmissible gastroenteritis virus in pigs, Am. J. Vet. Res. 43:77-81.

Cox, E., Hooybergh, J., and Pensaert, M. B., 1990, Sites of replication of a porcine respiratory coronavirus related to transmissible gastroenteritis virus, Res. Vet. Sci. 48:165-169. 
Delmas, B., Gelfi, J., and L'Haridon, R., et al., 1992, Aminopeptidase $\mathrm{N}$ is a major receptor for the enteropathogenic coronavirus TGEV, Nature. 357:417-420.

Doyle, L. P., and Hutchings, L. M., 1946, A transmissible gastroenteritis in pigs, J. Am. Vet. Med. Assoc. 108:257-259.

Frederick, G. I., Bohl, E. H., and Cross, J. E., 1976, Pathogenicity of an attenuated strain of transmissible gastroenteritis virus for newborn pigs, Am. J. Vet. Res. 42:1163-1169.

Halbur, P. G., Paul, P. S., Vaughn, E. M., and Andrews, J. J., 1993, Experimental reproduction of pneumonia in gnotobiotic pigs with porcine respiratory coronavirus isolate AR310, J. Vet. Diagn. Invest. 5:184-188.

Halbur, P. G., Andrews, J. J., Huffman, E. L., et al., 1994, Development of a streptavidin-biotin immunoperoxidase for the detection of porcine reproductive and respiratory syndrome virus antigen in porcine lung, $J$. Vet. Diagn. Invest. 6:254-257.

Hill, H. T., Biwer, J. D., Woods, R. D., and Wesley, R. D., 1989, Porcine respiratory coronavirus isolated from two U.S. swine herds, Proc. Am. Assoc. Swine. Pract. 333-335.

Horzinek, M. C., Lutz, H., and Pedersen, N. C., 1982, Antigenic relationships among homologous structure polypeptides of porcine, feline, and canine coronaviruses, Infect. Immun. 37:1148-1155.

Jackwood, D. J., Bae, I., Jackwood, R. J. et al., 1993, Transmissible gastroenteritis virus and porcine respiratory coronavirus molecular characterization of the $\mathrm{S}$ gene using cDNA probes and nucleotide sequence analysis, Adv. Exp. Med. Biol. 342:43-48.

Jin, L., Hemperly, J. J., and Lloyd, R. V., 1991, Expression of neural cell adhesion molecule in normal and neoplastic human neuroendocrine tissues, Am. J. Pathol. 138:961-969.

La Bonnardiere, C., and Laude, H., 1983, Interferon induction in rotavirus and coronavirus infections: a review of recent results, Ann. Rech. Vet. 14:507-511.

Larochelle, R., and Mogar, R., 1993. The application of immunogold silver staining (IGSS) for the detection of the transmissible gastroenteritis virus in fixed tissue, J. Vet. Diagn. Invest. 5:16-20.

Laude, H., Van Reeth, K., and Pensaert, M., 1993, Porcine respiratory coronavirus: molecular features and virushost interactions, Vet.Res. 24:125-150.

Morin, M., Morehouse, L. G., Solorzano, R. F., and Olsen, L. D., 1973, Transmissible gastroenteritis in feeder swine: clinical, immunofluorescence and histopathological observations, Can. J. Comp. Med. 37:239-248.

O`Toole, D., Brown, I., Bridges, A., and Cartwright, S. F., 1989, Pathogenicity of experimental infection with 'pneumotropic' porcine respiratory coronavirus, Res. Vet. Sci. 47:23-29.

Paul, P. S., Halbur, P. G., and Vaughn, E. M., 1994, Significance of porcine respiratory coronavirus infection, Compend. Cont. Educ. Pract. Vet. 16:1223-1234.

Paul, P. S., Vaughn, E. M., and Halbur, P. G., 1992, Characterization and pathogenicity of a new porcine respiratory coronavirus strain AR310, Proc. Int. Pig. Vet. Soc. Congr. 12:92

Pensaert, M. B., Callebaut, P., and Vergote, J., 1986, Isolation of a porcine respiratory non-enteric coronavirus related to transmissible gastroenteritis, Vet. Quart. 8:257-261.

Pensaert, M. B., Haelterman, E. O., and Hinsman, E. J., 1970, Transmissible gastroenteritis of swine: Virus-intestinal cell interactions. II. Electron microscopy of the epithelium in isolated jejunal loops, Arch. Gesamte. Virusforsch. 31:335-351.

Rassachaert, D., Duarte, M., and Laude, H., 1990, Porcine respiratory coronavirus differs from transmissible gastroenteritis virus by a few genomic deletions, J. Gen. Virol. 71:2599-2607.

Rassachaert, D., and Laude, H., 1987. The predicted primary structure of the peplomer protein E2 of the porcine coronavirus transmissible gastroenteritis virus, J. Gen. Virol. 68:1883-1890.

Rossen, J. W., Bekker, C. P., Voorhout, W. F. and et al., 1994, Entry and release of transmissible gastroenteritis coronavirus are restricted to apical surfaces of polarized epithelial cells, J. Virol. 68:7966-7973.

Saif, L. J., and Wesley, R. D., 1994, Transmissible gastroenteritis, In: A. D. Leman, B. E. Strauss, W. L. Mengeling, S. D‘Allaire, D. J. Taylor (Eds), Diseases of swine, 7th ed., lowa State University Press, Ames, IA, pp. $362-386$.

Sanchez, C. M., Gebauer, F., Sune, C., and Mendez, A. et al., 1992, Genetic evolution and tropism of transmissible gastroenteritis coronavirus, Virol. 190:92-105.

Sherpherd, R. W., Butler, D. G., Cutz, E., and Gall, D. G., 1979, The mucosal lesion in viral enteritis: extent and dynamics of the epithelial response to virus invasion in transmissible gastroenteritis of piglets, Gastroenterology 76:770-777.

Shockley, L. J., Kapke, P. A., Lapps, W., and Brian, D. A. et al., 1987, Diagnosis of porcine and bovine enteric coronavirus infections using cloned cDNA probes, J. Clin. Micro. 25:1591-1596.

Sirinarumitr, T., Paul, P. S., Kluge, J. P., and Halbur, P. G., 1996, In situ hybridization technique for the detection of swine enteric and respiratory coronaviruses, transmissible gastroenteritis virus (TGEV) and porcine respiratory coronavirus (PRCV), in the formalin-fixed paraffin-embedded tissues, J. Virol. Methods. 56: 149-160 
Spaan, W., Cavanagh, D., and Horzinek, M. C., 1988, Coronaviruses: structure and genome expression, J. Gen. Virol. 69:2939-2952.

Thake, D. C., 1968, Jejunal epithelium in transmissible gastroenteritis of swine (an electron microscopic and histochemical study), Am. J. Pathol. 53:149-168.

Van Nieustadt, A. P., and Pol, J. M. A., 1989, Isolation of a TGE virus-related respiratory coronavirus causing fatal pneumonia in pig, Vet. Rec. 124:43-44.

Vaughn, E. M., Halbur, P. G., and Paul, P. S., 1996, The use of nonradioactive cDNA probes to differentiate porcine respiratory coronavirus and transmissible gastroenteritis virus isolates, J. Vet. Diagn. Invest.

Vaughn, E. M., Halbur, P. G., and Paul, P. S., 1995, Sequence comparison of porcine respiratory coronavirus isolates reveals heterogeneity in the S, 3, 3-1 genes, J. Virol. 69:3176-3184.

Vaughn, E. M., Halbur, P. G., and Paul, P. S., 1994, Three new isolates of porcine respiratory coronavirus with various pathogenicities and spike (S) gene deletions, J. Clin. Microbiol 69:1809-1812.

Vaughn, E. M., and Paul, P. S., 1993, Antigenic and biological diversity among transmissible gastroenteritis virus isolates of swine. Vet. Microbiol. 36:333-347.

Wagner, J. E., Beamer, P. D., and Restic, M., 1973, Electron microscopy of intestinal epithelial cells of piglets infected with a transmissible gastroenteritis virus, Can. J. Comp. Med. 37:177-188.

Wesley, R. D., Woods, R. D., Hill, H. T., and Biwer, J. D., 1990, Evidence for a respiratory coronavirus antigenically similar to transmissible gastroenteritis in the United States, J. Vet. Diagn. Invest. 2:312-317.

Wesley, R. D., Woods, R. D., and Cheung, A. K., 1991a, Genetic basis for the pathogenesis of transmissible gastroenteritis virus, J. Virol. 64:4761-4768.

Wesley, R. D., Wesley, I. V., and Woods, R. D., 1991b, Differentiation between transmissible gastroenteritis virus and porcine respiratory coronavirus using a cDNA probe, J. Vet. Diagn. Invest. 3:29-32.

Weingartl, H., and Derbyshire, J. B., 1994, Evidence of a putative second receptor for porcine transmissible gastroenteritis virus on the villous enterocytes of newborn pigs, J. Virol. 68:7253-7259.

Weingartl, H., and Derbyshire, J. B., 1993, Binding of porcine transmissible gastroenteritis virus by enterocytes from newborn and weaned piglets, Vet. Microbiol. 35:1163-1169.

Woods, R. D., Cheville, N. F., and Gallagher, J. E., 1981, Lesions in the small intestines of newborn pigs inoculated with porcine, feline, and canine coronavirus, Am. J. Vet. Res. 42:1163-1169. 